\title{
Comparison of thermal tolerance in Collembola (Hexapoda) inhabiting soil and subterranean habitats
}

\author{
Natália Raschmanováł, Vladimír Šustr§, L'ubomír Kováč \\ ‡ Department of Zoology, Institute of Biology and Ecology, Faculty of Science, P. J. Šafárik University, Košice, Slovakia \\ $\S$ Institute of Soil Biology, Biology Centre CAS, České Budějovice, Czech Republic
}

Corresponding author: Lubomír Kováč (lubomir.kovac@upjs.sk)

Received: 12 Oct 2018 | Published: 19 Oct 2018

Citation: Raschmanová N, Šustr V, Kováč L, Parimuchová A, Devetter M (2018) Comparison of thermal tolerance in Collembola (Hexapoda) inhabiting soil and subterranean habitats. ARPHA Conference Abstracts 1: e30509. https://doi.org/10.3897/aca.1.e30509

\section{Abstract}

We hypothesized that trogloxenes inhabiting surface habitats, thermally fluctuating environment, would tolerate wide temperature ranges. We expected that the temperature tolerances would diminish over categories trogloxene - subtroglophile - eutroglophile troglobiont as a result of the degree of adaptation to subterranean environment that is characteristic with thermally stable conditions. We also assumed that body size may play crucial role in tolerance of Collembola to high and low temperature. Eighteen species of all four categories were exposed to one-hour survival laboratory test. The impact of temperature, species and species-temperature interaction on the cold and heat survival was statistically significant. The species heat tolerance significantly increased with increasing cold tolerance. In general, decrease in cold and heat tolerance was shown from trogloxenes, over subtroglophiles and eutroglophiles to troglobionts. Cryptic species Folsomia sp. among trogloxenes and Ceratophysella sigillata, Hypogastrura crassaegranulata among subtroglophiles were highly heat- and also cold-resistant, showing wide ecological plasticity. Subtroglophilous Tetrodontophora bielanensis and Lepidocyrtus violaceus, eutroglophilous Heteromurus nitidus and troglobiont Protaphorura janosik were the most cold-sensitive species, and all troglobionts and eutroglophilous Pygmarrhopalites pygmaeus as the most heat-sensitive species. Species belonging to ecological groups not 
or less associated to cave environment (trogloxenes and subtroglophiles) showed wider range of temperature tolerance in comparison with more cave adapted species (eutroglophiles and troglobionts), tested by ANOVA. Cold resistance decreased significantly with increasing body length, indicating that body size plays an important role in temperature tolerances of arthropods inhabiting soil and subterranean habitats.

\section{Keywords}

thermal tolerance, Collembola, soil, subterranean habitats, life forms, body size

\section{Presenting author}

Lubomír Kováč

\section{Presented at}

$24^{\text {th }}$ International Conference on Subterranena Biology, 20-24 August, Aveiro, Portugal 